\title{
Opening the Landsat Archive
}

On April 21, 2008, the United States Geological Survey (USGS) announced plans to provide all archived Landsat scenes at no charge to all users. By early December of that year, all Landsat data were available for free.

Newly acquired scenes with 60 or less percent cloud cover are automatically processed. Any archived scene, regardless of cloud cover, can be processed upon request and made available for download.

All standard data products are processed using the Level 1 Product Generation

System (LPGS)* with the following parameters applied:

- Pixel size

$\circ$ ETM+ and TM multispectral and thermal: 30 meters

- MSS: 60 meters

- ETM+ panchromatic band: 15 meters

- GeoTIFF output format

- Cubic Convolution (CC) resampling method

- Universal Transverse Mercator (UTM) map projection

- Polar Stereographic projection for Antarctica scenes

- MAP (north up) image orientation

- File transfer protocol (FTP) download only

ETM+: Enhanced Thematic Mapper Plus, Landsat 7

TM: Thematic Mapper, Landsats 4 and 5

MSS: Multi-Spectral Scanner, Landsats 1, 2, 3, 4, and 5

* A small number of Landsat TM scenes are still processed using the

heritage National Land Archive Production System (NLAPS).

Although most data are processed as a Level 1T (L1T-precision and terrain corrected) product, certain scenes do not have ground-control or elevation data necessary for precision or terrain correction, respectively. In these cases, the best level of correction is applied (Level 1G-systematic or Level 1Gt-systematic with terrain). Specific L1T scenes are available for most of the globe under the Global Land Surveys (http://landsat.usgs.gov/science GLS.php). All data products have consistent and up-to-date radiometric algorithms applied.

Landsat scenes can be viewed, requested, and downloaded from EarthExplorer (http://earthexplorer.usgs.gov) or USGS Global Visualization Viewer (GloVis) (http://glovis.usgs.gov).

More details and updates on the status of Landsat missions and imagery can be found at $h$ ttp://landsat.usgs.gov.

Please contact USGS EROS Customer Services at 1-800-252-4547, or email custserv@usgs.gov for more information. 